ISSN 0258-7122

Bangladesh J. Agril. Res. 33(3) : 639-645, December 2008

\title{
EFFICACY OF MAJOR NUTRIENTS IN RICE PRODUCTION
}

\author{
A.L. SHAH ${ }^{1}$, M.R. ISLAM ${ }^{2}$, M M HAQUE $^{3}$, \\ M. ISHAQUE ${ }^{4}$ AND M.A.M. MIAH ${ }^{5}$
}

\begin{abstract}
Nutrients efficacy means increased rice yield upon soil fertilization. Purposefully a particular nutrient stress was created in soil through missing element technique from complete treatment (NPKSZn) and its reserve management (addition of omitted nutrient) effect in increasing yield was considered as a measuring stick of nutrients efficacy. The omission of all NPKSZn fertilizers from complete treatment (NPKSZn) drastically decreased yield than continuously fertilized complete treatment. Similar extent of' yield increase was observed when all NPKSZn fertilizer was applied in absolute control plot indicating that every soil needs complete addition of NPKSZn fertilizers irrespective of seasons whether the plot was continuously fertilized or not. The amount of yield increase obtained upon a missing element fertilization nearly equivalent amount of yield loss as aloofness of that particular nutrient as compared to complete fertilization. It means lhc efficacy of each essential nutrient might increase yield in a similar manner depending on their magnitude of deficiency level in the soil. Continuous application of N@120 kg/ha in boro and 80 kg/ha in T.aman with PKSZn @ 25-33-20-05 kg/ha per season improve total soil N, S and Zn. But exchangeable K decreased compared to initial soil status. In case of $\mathrm{P}$ fertilization, this rate maintained the initial soil $\mathrm{P}$ level. However, available $\mathrm{Zn}$ was found well above critical level even after $45^{\text {th }}$ crop as because of high initial soil available $\mathrm{Zn}$ level.
\end{abstract}

Key Words: Nutrient efficacy, rice yield, soil fertilization.

\section{Introduction}

Nitrogen, P. K, S and Zn, of which the three major elements are most important both in the terms of the extent of their deficiencies in the soils, and in terms of their potential for crop yield increases or losses. Nitrogen is the nutrient element limiting growth in most of the rice soils (Savant and Datta, 1982), and there have been indications that many rice soils of Bangladesh are becoming deficient in $\mathrm{P}$, $\mathrm{K}, \mathrm{S}$ and $\mathrm{Zn}$ (BARC, 2005). The decline in productivity of rice and wheat with continuous cropping was related to deficiency of P, K, S, Zn and imbalanced nutrition (Kumar and Yadav, 2005). Purposefully, a particular nutrient stress created through missing element technique from complete treatment and its reverse management (addition of omitted nutrient in half part of the plot) effect in increasing yield was considered as a measuring stick of nutrient efficacy. The objective of this long-term study was to measure the extent of each major

${ }^{1-5}$ Soil Science Division, BRRI, Joydebpur, Gazipur- 1701, Bangladesh. 
nutrient exclusion effect in soil to decrease yield and simultaneously their application in soil to increase rice yield.

\section{Materials and Method}

The missing element technique experiment was initiated in 1985 boro season as long-term basis with 12 treatment combinations (NPKSZn as complete treatment, omission of one or more nutrients from complete nutrient i.e., N, -P,-K,-S,-Zn,PK,-SZn, -PKSZn. - PSZn, and -KSZn, including one absolute control treatment. The experimental design was RCB with four replications. The variety BR3 was used in boro season and BR 11 was in T. Aman season. In 2001, each treatment again was divided into 2 parts i.e., one part remains as previous treatment and the other remaining half part imposed with omitted nutrient considered as reverse management to measure the magnitude of increasing yield. However, decreased yield was calculated from complete treatment yield minus omission nutrient plot yield. For the convenience, 7 treatments were actively considered for meaningful interpretation. Seven years' mean yield data of missing element and reverse management were statistically analyzed separately in RCB design. Beside these, calculated increase and decrease yield data also analyzed for t-test. However, initial soils. after $45^{\text {th }}$ crops soil samples of absolute control and complete fertilizer treatment were analyzed for total $\mathrm{N}$ (\%), available P, 55, Zn (mg kg-1) and exchangeable K (meg/100 g soil).

\section{Results and Discussion}

It appears from the Table 1 that the long-term missing of major nutrient individually from the complete treatment (NPKSZn) significantly decreased yield and still significantly higher than absolute control treatment. Yadav et al. (1998) showed that significant yield declines in rice in the treatments with imbalanced application of N, P and K fertilizers (120-0-0, 120-35-0, 120-0-33). On the other hand, the addition of omitted each major nutrient under reverse management produced yield similar to complete treatment. When withdrawl of NPKSZn fertilizer from complete treatment the yield of rice drastically decreased and slightly higher than long-term absolute complete treatment even through it was statistically at par. Significant yield increase was observed with addition of each omitted major nutrients through reserve management and gave nearly equivalent yield as complete fertilization i.e, continuous NPKSZn fertilizer treatment. Similar extent of yield increase was als observed when all NPKSZn fertilizer was applied in absolute control plot indicating that every soil needs complete addition ol NPKSZn fertilizers irrespective of seasons whether the plot was continuously fertilized or not. It means that when a soil fertilized with optimum dose along with the coverage of major nutrient element produced maximum yield. However, the omission or addition of $\mathrm{S}$ and $\mathrm{Zn}$ did not influence grain yield than complete 
treatment meaning these two nutrient elements were not yield limiting factor under the experimental soil condition. The yield increase or decrease response behaviour had similarities with the previous long-term yearly yield data (Fig. 1).

Table 1. Effect of long-term missing of NPKSZn singly and their reserve management on rice yield during boro and T. Aman season (Data average of 6 yrs), BARI farm, Gazipur.

\begin{tabular}{l|l|l|l|l}
\hline \multirow{2}{*}{ Treatments } & \multicolumn{4}{c}{ Grain yield (kg/ha) } \\
\cline { 2 - 5 } & \multicolumn{1}{c|}{$\begin{array}{c}\text { Missing } \\
\text { nutrients }\end{array}$} & $\begin{array}{c}\text { Reverse } \\
\text { Management }\end{array}$ & $\begin{array}{c}\text { Missing } \\
\text { nutrients }\end{array}$ & $\begin{array}{c}\text { Reverse } \\
\text { Management }\end{array}$ \\
\hline NPKSZn & 5.04 & 2.63 & 3.87 & 3.18 \\
$-\mathrm{N}$ & 3.60 & 5.11 & 3.26 & 3.85 \\
$-\mathrm{P}$ & 3.73 & 5.20 & 3.43 & 3.95 \\
$-\mathrm{K}$ & 3.78 & 5.23 & 3.28 & 3.80 \\
$-\mathrm{S}$ & 5.55 & 5.16 & 3.80 & 3.76 \\
-Zn & 5.17 & 5.21 & 3.72 & 3.92 \\
Control & 2.25 & 5.05 & 3.14 & 3.94 \\
\hline LSD (0.05) & 0.39 & 0.35 & 0.28 & 0.23 \\
CV (\%) & 8.0 & 6.3 & 6.8 & 5.2 \\
\hline
\end{tabular}

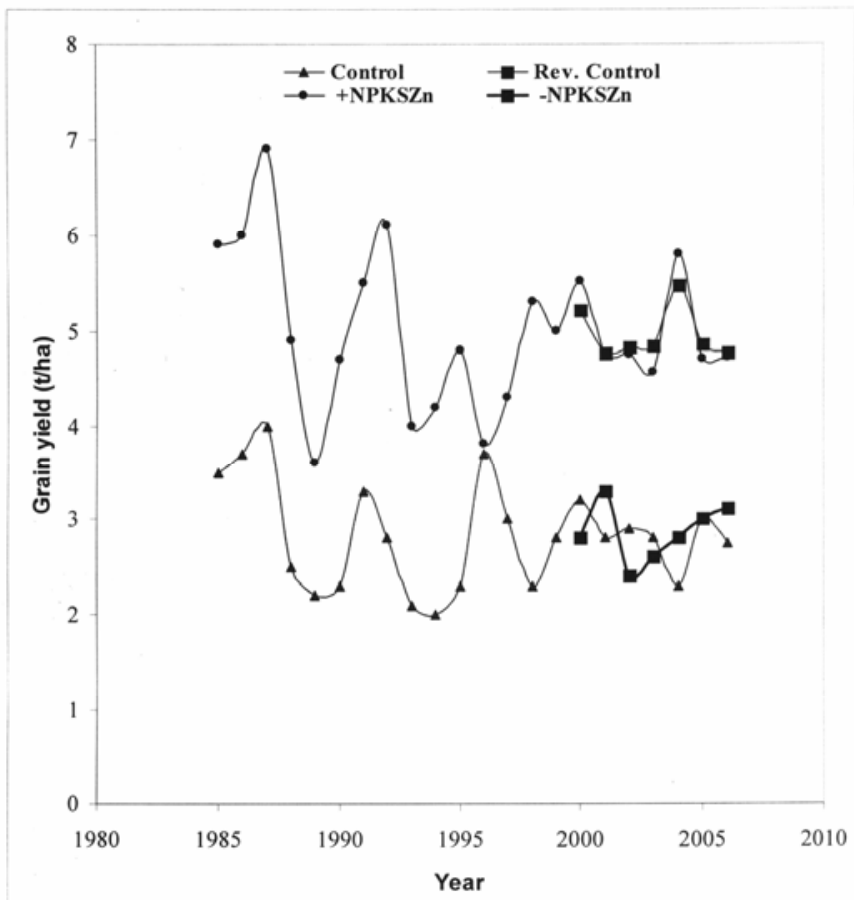

Fig. 1. Long-term yield trend scenario of same treatment in same plot. 
The amount of yield increase obtained upon a missing element fertilization of $\mathrm{N}$, P or K was nearly equivalent to the amount of yield loss as aloofness of that particular nutrient as compared to complete fertilization (Fig. 2 and 3). The rate of increase and decrease of rice yield with time was higher but the corresponding both ways response behaviour was more or less same. However, the observed average yield decrease and increase over six years of each major nutrient omission or addition from complete treatment (NPKSZn) was statistically insignificant (Table 2). Nitrogen and $\mathrm{P}$ response were observed since inception of this experiment and after 7th crops $\mathrm{K}$ deficiency vas observed in terms of yield increase in $\mathrm{K}$ omission plot. It implies that the efficacy of each major nutrient to increase yield mode was similar, but the magnitude of yield increase depended on the deficiency level of each nutrient element in soil.
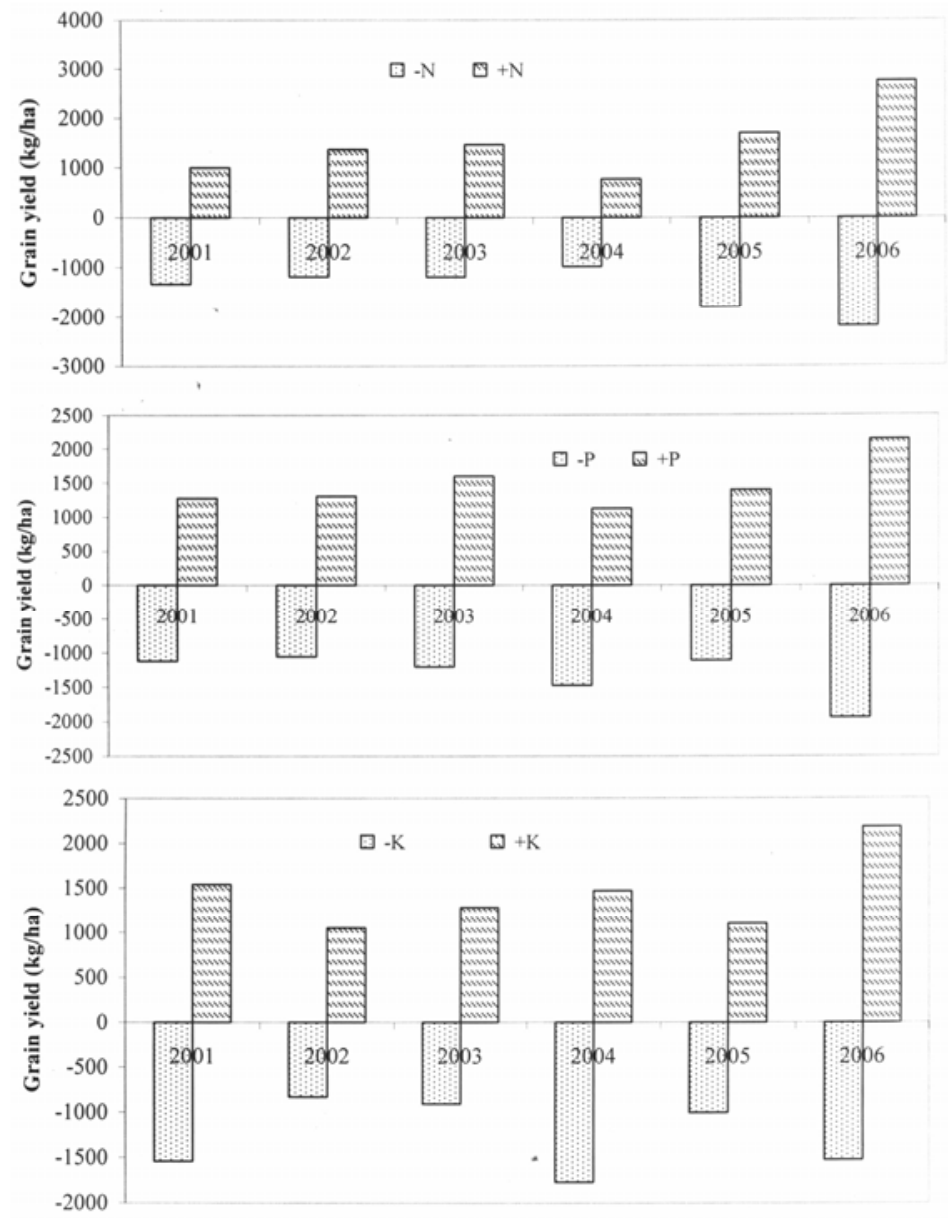

Fig. 2. Effect of omission and addition of major nutrient on grain yield in Boro season (BR 3). 
Table 2. Rice yield decrease or increases (kg/ha; 6 yrs average) due to omission or addition of major nutrients from complete treatment (NPKSZn).

\begin{tabular}{l|l|l|l|l|l|r}
\hline \multirow{2}{*}{$\begin{array}{l}\text { Nutrient } \\
\text { elements }\end{array}$} & \multicolumn{3}{|c|}{ Boro } & \multicolumn{3}{c}{ T. Aman } \\
\cline { 2 - 7 } & Decrease & Increase & T-test & Decrease & Increase & T-test \\
\hline $\mathrm{N}$ & 1445 & 1511 & $\mathrm{~ns}$ & 558 & 538 & $\mathrm{~ns}$ \\
$\mathrm{P}$ & 1313 & 1476 & $\mathrm{~ns}$ & 436 & 512 & $\mathrm{~ns}$ \\
$\mathrm{~K}$ & 1262 & 1437 & $\mathrm{~ns}$ & 593 & 523 & $\mathrm{~ns}$ \\
\hline
\end{tabular}
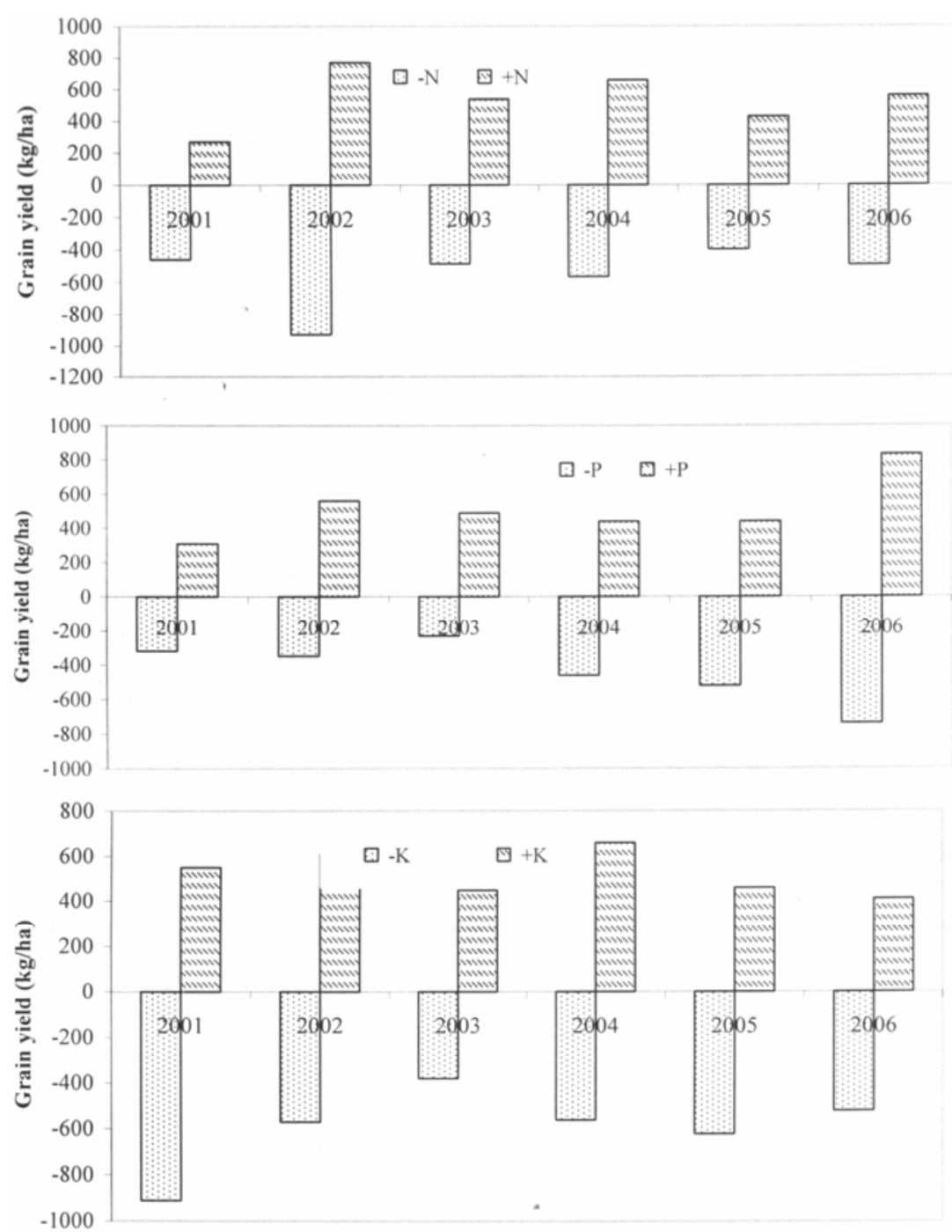

Fig. 3. Effect of omission and addition of major nutrients on grain yield in T. Aman season (BR 11). 
Continuous application of N @ 120 kg/ha in boro and 80 kg/ha in T.Aman seasons with PKSZn 25-35-20-50 kg/ha improved total soil N, available $\mathrm{S}$ and $\mathrm{Zn}$ in soil after 45th crop harvest (Table 3). In case of $\mathrm{P}$ fertilization, this rate, maintained the initial soil available $\mathrm{P}$ level. But exchangeable Kdecreased compared to initial soil status. A similar result was reported by Bhyian et al. (1991) in 10 yrs long -term experiment. Dobermann et al. (1996) also obtained a highly negative $\mathrm{K}$ balance in the IRRI long-term experiment, even where NPK treatments were applied, because the average $40 \mathrm{~kg} \mathrm{~K} / \mathrm{ha}$ was not significant for rice to maintain $\mathrm{K}$ uptake of about $100 \mathrm{~kg} / \mathrm{ha}$. However, continuous $\mathrm{Zn}$ fertilization in complete treatment (NPKSZn) builds up available Zn in soil level, but without Zn application its level decreased as found in absolute control plot even though this level is still well above critical level. It indicates that fertilization is a Continuous process, but it needs change with time depending upon kind and amount of fertilization in rice cultivation practiced.

Table 3. Changes of soil nutrients over initial soil due to omission and addition management of nutrients after $45^{\text {th }}$ crop.

\begin{tabular}{l|c|c|c|l|l|l}
\hline Treatments & $\begin{array}{c}\text { Soil pH } \\
(1: 25)\end{array}$ & $\begin{array}{c}\text { Total N } \\
(\%)\end{array}$ & $\begin{array}{c}\text { Olsen P } \\
(\mathrm{mg} / \mathrm{kg})\end{array}$ & $\begin{array}{c}\text { Exch. K } \\
(\mathrm{meq} / 100 \mathrm{~g})\end{array}$ & $\begin{array}{c}\text { Available S } \\
(\mathrm{mg} / \mathrm{kg})\end{array}$ & $\begin{array}{c}\text { Available } \\
\text { Zn }(\mathrm{mg} / \mathrm{kg})\end{array}$ \\
\hline NPKSZn & 6.95 & 0.13 & 10.2 & 0.14 & 15.5 & 5.04 \\
Control & 6.77 & 0.09 & 5.7 & 0.08 & 11.0 & 2.22 \\
Initial soil & 6.78 & 0.08 & 9.8 & 0.18 & 9.0 & 3.00 \\
Critical limit & - & 0.12 & 8.0 & 0.12 & 10.0 & 0.6 \\
\hline
\end{tabular}

\section{Conclusion}

Rice yield increase obtained upon a particular nutrient element fertilization depends on the intensity of deficiency level of that particular nutrient prevails in the soil being used for cultivation. The study also highlights the importance of complete or balance fertilization for maximizing rice yield and higher $\mathrm{K}$ fertilization than existing rate to minimizing $\mathrm{K}$ mining over times.

\section{References}

BARC (Bangladesh Agricultural Research Counsil). 2005. Fertilizer Recommendation Guide, Soils Publication No.45. p.26.

Bhyian, N. I,, A. L. Shah and G. M. Panaullah.1991. Effect of NPK fertilization on the grain yield of transplant rice and soil fertility - a long term study. Bangladesh J Soil Sci. 2 (1 and 2): 41-99.

Doberrnann, A., P. Cta. Cruz and K. G. Cassman. 1996. Fertilizer inputs, nutrient balance and soil nutrient supplying power in intensive irrigated rice system. 1. Potassium uptake and K balance. Nutr. Cyci. Agroecosyst. 40: 1-10. 
Kumar, A and D. S. Yavdav. 2005. Influence of continuous cropping and fertilization on nutrient availibility and productivity of alluvial soil. J. Indian Soc. Soil. Sci. 55(2):194-198.

Savant, N. K. and S. K. Dc Datta. 1982. Nitrogen transformation in wetland rice soils. Adv.Agron. 35: 241-302.

Yadave, R. L., D. S. Ydav, R. M. Singh and A. Kumar. 1998. Long-term eflbcts of inorganic fertilizer inputs on crop productivity in a rice-wheat cropping system. Nutr. Cycl. Agroecosyst. 51: 193-200. 